\title{
KVALITETA ŽIVOTA STUDENATA SVEUČILIŠTA U MOSTARU
}

\author{
Dajana Šimić ${ }^{1}$, Dragan Babićc ${ }^{1,2}$ \\ ${ }^{1}$ Fakultet zdravstvenih studija, Sveučilište u Mostaru, Bosna i Hercegovina \\ ${ }^{2}$ Klinika za psihijatriju, Sveučilišna klinička bolnica Mostar, Bosna i Hercegovina \\ Rad je primljen 22.2.2017. Rad je recenziran 15.3.2017. Rad je prihvaćen 26.4.2017.
}

\section{SAŽETAK}

UVOD: Studenti se suočavaju s mnogim opterećenjima usljed čega imaju nedostatak vremena za odmor i san, fizičke i rekreativne aktivnosti, ali i promjenjene zdravstvene navike što vodi k nepravilnoj prehrani, pretjeranoj uporabi alkoholnih pića, pušenju i uporabi psihoaktivnih tvari. Sve to može utjecati na njihovu kvalitetu življenja.

CILJ: Ispitati kvalitetu života studenata Sveučilišta u Mostaru.

ISPITANICI I METODE: Istraživanje je provedeno slučajnim odabirom među studentskom populacijom oba spola. Ispitnu skupinu činili su studenti koji žive kao podstanari $(\mathrm{N}=100)$, a kontrolnu skupinu činili su studenti koji žive s roditeljima $(\mathrm{N}=100)$. Za istraživanje korišteni su upitnici: Sociodemografski upitnik i Standardizirani upitnik za procjenu kvalitete života (Short from health survey-36, SF-36).

REZULTATI: Statistički značajno veći broj studenata koji žive kod roditelja puši, međutim puše manji broj cigareta, nego studenti koji žive kao podstanari. Studenti koji žive kao podstanari u većem postotku piju alkoholna pića i značajno češće piju od studenata koji žive kod roditelja. Studenti koji žive kod roditelja imaju statistički značajno bolju kvalitetu života u vidu fizičkog funkcioniranja, percepcije općeg zdravlja i tjelesne boli.

ZAKLJUČAK: Studenti koji žive kod roditelja imaju bolju kvalitetu života u odnosu na studente koji žive kao podstanari.

Ključne riječi: kvaliteta života, studenti, Sveučilište u Mostaru

Kontakt za razmjenu informacija:

Dajana Šimić, dipl.med.sestra

e-mail: simic.dajana@live.com

\section{UVOD}

Kvaliteta života ima bitnu ulogu u svakodnevnici pojedinca. Kroz zadnjih dvadesetak godina zabilježen je značajan napredak u istraživanju i procjeni kvalitete života. Svjetska zdravstvena organizacija (SZO) definira kvalitetu života kao pojedinčevu percepciju pozicije u specifičnom kulturološkom, društvenom, te okolišnom kontekstu (1). Studenti predstavljaju potencijalne profesionalce sa značajnim ulogama u budućnosti, te iz tog razloga su njihovi stavovi u pogledu zdravstvenih navika od velike važnosti (2). Studenti se suočavaju s izazovom da promijene svoje prethodne navike s ciljem da se izbore $s$ akademskim opterećenjem i stresom koji nosi njihovo obrazovanje. To često podrazumijeva nedostatak vremena za odmor i san, fizičke i rekreativne aktivnosti, ali i promijenjene zdravstvene navike, što vodi k nepravilnoj prehrani, pretjeranoj konzumaciji alkoholnih pića, pušenju i konzumaciji psihoaktivnih tvari (3). Tijekom povijesti definicije i mjerenje kvalitete života uvelike su se razlikovale i mijenjale. Sredinom dvadesetog stoljeća pod kvalitetom života se uglavnom podrazumijevao životni standard, a istraživanja na tu temu bila su rađena u području ekonomije. Šezdesetih godina dvadesetog stoljeća počelo se jasno razlikovati subjektivne od objektivnih pokazatelja osobne kvalitete života. Sedamdestih godina istraživanja kvalitete života usmjerila su se na subjektivne pokazatelje kvalitete života. Usmjerenost na pojednica karakterizira i današnji pristup $\mathrm{u}$ istraživanjima kvalitete života (4). 
U procjenjivanju kvalitete života ispitaniku treba biti dana mogućnost da identificira područja života koja su njemu važna, te da iskaže u kojoj mjeri svako od navedenih sudjeluje u sveukupnoj kvaliteti života (5). Brojni su isntrumenti kojima se obuhvaća i mjeri konstrukt kvalitete života povezan sa domenom zdravlja, a može ih se podijeliti u tri skupine. Prvu skupinu čine opći upitnici, kojiima se obuhvaća veći broj područja kvalitete života. Takva vrsta upitnika ima najširu upotrebu, te se koristi kod različitih bolesti, ali i kod zdrave populacije ljudi gdje se ispituju demografske i međukulturalne razlike u kvaliteti života. Često se koriste neki od instrumenata ove vrste, kao što su: Profil učinka bolesti (Sickness Impact Profile), Upitnik za samoprocjenu zdravstvenog stanja (Short form health survey, SF-36) i Upitnik kvalitete života Svjetske zdravstvene organizacije (The World Health Organization Quality of Life Instrument) $(6,7,8)$. Drugu skupinu čine instrumenti vezani uz točno određene bolesti, razvijeni za specifičnu uporabu među pacijentima sličnih tegoba. Neki od njih konstruirani su za tegobe vezane uz oboljenja od dijabetesa, artritisa, srčanih bolesti i sl., a upitnicima se zahvaćaju one domene kvalitete života koje su značajne za pojedino oboljenje. Kod pacijenata oboljelih od artritisa kvaliteta života često se ispituje Skalom za mjerenje utjecaja oboljenja od artritisa (Arthritis Impact Measurement Scale) (9). Treću skupinu instrumenata čine utjecaji nekih domena na kvalitetu života, npr. utjecaj depresivnosti. Primjer ove vrste upitnika je Beckov inventar depresivnosti (Beck Depression Inventory) (10).

Objektivni pristup proučavanja kvalitete življenja tradicionalniji je i zasnovan na nizu pretpostavki o tome što život čini dobrim, te je pretežito usredotočen na identifikaciju vanjskih uvjeta koji vode poboljšanju života. Taj pristup koristi različite događaje (npr. rat, razvod), okolinske uvjete (npr. sustav zdravstvene i socijalne zaštite) i demografske čimbenike (npr. dob, spol, radni status) kao indikatore kvalitete življenja, odnosno, nastoji zaključiti o kvaliteti življenja na osnovu objektivnih karakteristika pojedinaca i uvjeta u kojima žive. Istraživanja koja proučavaju ovu vrstu indikatora tipično uključuju velike nacionalno reprezentativne uzorke ispitanika koji pripadaju različitim socioekonomskim skupinama $(11,12)$. Subjektivni pristup proučavanju kvalitete življenja polazi od pretpostavke da je važno imati uvid u kognitivne i afektivne reakcije pojedinca na njegov/njezin vlastiti život u cjelini, ali i na pojedine aspekte života (npr. zdravlje, odnosi, rad), kako bismo razumjeli kvalitetu življenja i subjektivnu dobrobit pojedinca (13). Taj pristup podrazumijeva izravno mjerenje doživljaja dobrobiti, pri čemu se najčešće radi o samoprocjeni pojedinih komponenata ili cjelokupnog doživljaja subjektivne dobrobiti. U odnosu na objektivni, subjektivni pristup je složeniji, ali novija istraživanja pokazuju da je relevantniji i korisniji jer su subjektivni indikatori bolji prediktori globalne procjene života od objektivnih, što je razumljivo ako se uzmu u obzir defnicije koncepta kvalitete življenja $(14,15)$. Pojedinac najbolje sam za sebe može odrediti koliko je sretan i zadovoljan u svom životu u cijelosti ili u pojedinim životnim područjima. Poteškoće sa subjektivnim pristupom odnose se prije svega na probleme mjerenja i stabilnost subjektivne dobrobiti. Konkretno, ljudi se međusobno uvelike razlikuju po važnosti koju pridaju određenom području života. Svaka osoba ima jedinstvenu kombinaciju za pojedina životna područja, utemeljenu na svojim iskustvima i socijalnim odnosima, što utječe na njegovu globalnu procjenu kvalitete življenja (16).

Studenti su populacija mladih koju, iako pripada dijelu najzdravijeg stanovništva treba promatrati kao vrlo osjetljiv segment društva (17). Izazovi i mogućnosti s kojima se mladi susreću tijekom svog studiranja su brojni i po mnogo čemu specifični. Živjeti kao student uključuje različite promjene na kognitivnom, emocionalnom i društvenom području (18). Studenti se prilagođavaju novim potrebama unutarnjeg i vanjskog okruženja i tada se pod različitim utjecajima formiraju stavovi prema religiji, zdravlju i rizičnom ponašanju,što je osnova za stanje kvalitete života u starijim godinama. Zaštita zdravlja mladih ljudi u svim njegovim aspektima (fizičkim, mentalnim i socijalnim) predstavlja snažnu obavezu i odgovornost svih segmenata društva (17). Cilj ovog istraživanja bio je ispitati kvalitetu života studenata 
Sveučilišta u Mostaru, onih koji žive s roditeljima i onih koji žive kao podstanari.

\section{ISPITANICI I METODE}

Ispitanici su bili studenti Sveučilišta u Mostaru. Ispitnu skupinu činili su studenti koji žive kao podstanari ( $\mathrm{N}=100)$, a kontrolnu skupinu činili su studenti koji žive s roditeljima $(\mathrm{N}=100)$. $\mathrm{Za}$ istraživanje su korištena dva upitnika, a to su: Sociodemografski upitnik - sačinjen od općih pitanja: spol, dob, mjesto stanovanja, naziv studija, materijalne mogućnosti, ukupan broj članova obitelji i Standardizirani upitnik za procjenu kvalitete života (Short from health survey-36, SF-36). Upitnik SF-36 je namijenjen samoprocjeni psihičkog i fizičkog zdravlja, te socijalnog funkcioniranja. Sastoji se od 36 pitanja (čestica).

\section{REZULTATI}

U istraživanje je uključeno ukupno 200 studenata preddiplomskog studija Sveučilišta u Mostaru.

Tablica 1. Raspodjela ispitanika u odnosu na sociodemografske karakteristike

\begin{tabular}{|c|c|c|c|c|c|c|}
\hline & \multicolumn{4}{|c|}{ Stanovanje } & \multirow{3}{*}{$\chi^{2}$} & \multirow{3}{*}{$P$} \\
\hline & \multicolumn{2}{|c|}{ Privatno } & \multicolumn{2}{|c|}{ Roditelji } & & \\
\hline & $\mathrm{N}$ & $\%$ & $\mathrm{~N}$ & $\%$ & & \\
\hline Spol & & & & & 3,282 & 0,070 \\
\hline M & 26 & 26,0 & 39 & 39,0 & & \\
\hline Ž & 74 & 74,0 & 61 & 61,0 & & \\
\hline Fakultet & & & & & 14,757 & $0,002^{*}$ \\
\hline FZS & 93 & 93,0 & 76 & 76,0 & & \\
\hline FPMOZ & 5 & 5,0 & 6 & 6,0 & & \\
\hline FSR & 2 & 2,0 & 14 & 14,0 & & \\
\hline ATPF & 0 & 0,0 & 3 & 3,0 & & \\
\hline Gradevina & 0 & 0,0 & 1 & 1,0 & & \\
\hline Obrazovanje & & & & & 44,442 & $<0,001^{*}$ \\
\hline Zaposliti se & 77 & 77,0 & 31 & 31,0 & & \\
\hline Nastaviti školovanje & 21 & 21,0 & 66 & 66,0 & & \\
\hline Nešto drugo & 2 & 2,0 & 3 & 3,0 & & \\
\hline Pušenje & & & & & 5,013 & 0,025 \\
\hline NE & 58 & 58,0 & 74 & 74,0 & & \\
\hline DA & 42 & 42,0 & 26 & 26,0 & & \\
\hline Broj cigareta & & & & & 19,393 & $<0,001^{*}$ \\
\hline Nekoliko & 7 & 16,7 & 14 & 53,8 & & \\
\hline 10-tak & 5 & 11,9 & 7 & 26,9 & & \\
\hline
\end{tabular}

\begin{tabular}{lcccccc}
20 & 20 & 47,6 & 5 & 19,2 & & \\
$20-40$ & 10 & 23,8 & 0 & 0,0 & & \\
Alkohol & & & & & 6,583 & $\mathbf{0 , 0 1 0}$ \\
$\mathrm{NE}$ & 6 & 6,0 & 19 & 19,0 & & \\
DA & 94 & 94,0 & 81 & 81,0 & & \\
Koliko često & & & & & 11,161 & $\mathbf{0 , 0 0 2 ^ { * }}$ \\
Svaki dan & 2 & 2,1 & 0 & 0,0 & & \\
3 puta tjedno & 15 & 16,0 & 2 & 2,5 & & \\
Samo vikendom & 77 & 81,9 & 79 & 97,5 & & \\
\hline *Fisherov egzaktni test & & & & & &
\end{tabular}

Ispitanici koji žive kao podstanari u većem omjeru studiraju Fakultet zdravstvenih studija. Najviše studenata koji žive kao podstanari se izjasnilo da bi se nakon završetka školovanja zaposlilo, dok se najveći broj onih koji žive kod roditelja izjasnilo da će nastaviti školovanje. Značajno veći broj studenata koji žive kod roditelja puši, međutim puše manji broj cigareta, nego studenti koji žive kao podstanari. Studenti koji žive kao podstanari u većem postotku piju alkoholna pića i značajno češće piju od studenata koji žive kod roditelja. Sve navedene razlike su statistički značajne (Tablica 1).

Tablica 2. Raspodjela ispitanika u odnosu na kvalitetu života

\begin{tabular}{|c|c|c|c|c|c|c|}
\hline & \multicolumn{4}{|c|}{ Stanovanje } & \multirow{3}{*}{$\mathrm{t}$} & \multirow{3}{*}{$P$} \\
\hline & \multicolumn{2}{|c|}{ Privatno } & \multicolumn{2}{|c|}{ Roditelji } & & \\
\hline & $x$ & SD & $x$ & SD & & \\
\hline Fizičko funkcioniranje & 80,55 & 24,52 & 89,30 & 19,64 & 2,785 & 0,006 \\
\hline 0graničenja zbog fizičkih poteškoća & 68,50 & 36,69 & 75,51 & 32,14 & 1,433 & 0,153 \\
\hline $\begin{array}{l}\text { Ograničenja zbog emocionalnih } \\
\text { poteškoća }\end{array}$ & 72,67 & 39,18 & 79,33 & 32,40 & 1,311 & 0,191 \\
\hline Vitalnost & 61,20 & 17,58 & 65,10 & 16,08 & 1,637 & 0,103 \\
\hline Mentalno zdravlje & 70,20 & 15,29 & 74,12 & 15,18 & 1,820 & 0,070 \\
\hline Sociijalno funkcioniranje & 75,88 & 18,82 & 79,88 & 18,88 & 1,500 & 0,135 \\
\hline Tjelesna bol & 74,85 & 21,63 & 81,30 & 21,42 & 2,119 & 0,035 \\
\hline Percepcija općeg zdravlja & 65,30 & 18,24 & 73,40 & 16,79 & 3,268 & 0,001 \\
\hline
\end{tabular}

Studenti koji žive kod roditelja su postizali značajno više rezultate na skali fizičkog funkcioniranja, percepciji općeg zdravlja i tjelesnoj boli (Tablica 2). 
Tablica 3. Raspodjela ispitanika u odnosu na spolnu pripadnost

\begin{tabular}{|c|c|c|c|c|c|c|}
\hline & \multicolumn{4}{|c|}{ Spol } & \multirow{3}{*}{$\mathrm{t}$} & \multirow{3}{*}{$\mathrm{P}$} \\
\hline & \multicolumn{2}{|r|}{ M } & \multicolumn{2}{|c|}{$\check{L}$} & & \\
\hline & $\overline{X \square}$ & $S D$ & $\mathrm{X} \square$ & SD & & \\
\hline Fizičko funkcioniranje & 81,69 & 928,19 & 86,48 & 19,26 & 1,238 & 0,219 \\
\hline ograničenja zbog fizičǩh poteškoća & 72,66 & 636,66 & 671,67 & 33,71 & 0,188 & 0,851 \\
\hline ograničenja zbog emocionalnih poteškoća & 76,92 & 236,29 & 975,56 & 36,01 & 0,251 & 0,802 \\
\hline Vitanost & 65,38 & $8 \quad 17,15$ & 62,07 & 16,77 & 1,298 & 0,196 \\
\hline Mentalno zdravlje & 73,48 & 8 15,99 & 71,53 & 15,01 & 0,843 & 0,400 \\
\hline Socijalno funkcioniranje & 78,27 & 722,35 & 77,69 & 17,10 & 0,186 & 0,853 \\
\hline Tjelesna bol & 79,58 & 23,31 & 177,35 & 20,94 & 0,678 & 0,499 \\
\hline Percepcija općeg zdravlja & 71,77 & 18,80 & 68,19 & 17,48 & 1,325 & 0,187 \\
\hline
\end{tabular}

Nije bilo značajnih razlika u domenama kvalitete života među spolovima (Tablica 3).

\section{RASPRAVA}

U ovom radu smo istraživali kvalitetu života studenata koji žive kod roditelja u odnosu na studente koji žive kao podstanari. Ukupno je ispitano 200 studenata, od kojih 100 studenata žive kod roditelja i 100 studenata žive kao podstanari, te je u istraživanju bilo 65 (32\%) ispitanika muškog spola i 135 (68 \%) ženskog spola.

Analizom podataka pokazalo se da se studenti koji žive kao podstanari nakon završetka preddiplomskog studija žele zaposliti, dok studenti koji žive kod roditelja žele nastaviti svoje obrazovanje na višoj sveučilišnoj razini (Tab. 1 prikazana u rezultatima).

Statistički značajno veći broj pušača je među studentima koji žive kod roditelja, ali u manjim količinama puše cigarete, dok studenti koji žive kao podstanari su u manjem broju pušači, ali u većim količinama puše cigarete (Tab. 1 prikazana u rezultatima). Zastupljenost pušenja cigareta javlja se i u drugim istraživanjima (Kuznar-Kaminska i sur.). Epidemiološki podaci u Poljskoj pokazali su da studenti započinju redovito pušenje cigareta između 18. i 21. godine života (19).
Istraživanje iz 2001. godine (Steptoe A., Wardle J. i sur.) je pokazalo da $23 \%$ i $20 \%$ studenata iz zapadne i istočne Europe puše cigarete. Steptoe je sa svojim suradnicima 2002. godine pokazao da je prevalencija pušenja cigareta među europskim studentima iz 13 europskih zemalja u razdoblju od 10 godina porasla unatoč svjesnosti o povećanom zdravstvenom riziku (20).

Rezultati pokazuju da češće i u većim količinama alkoholna pića piju studenti koji žive kao podstanari u odnosu na one studente koji žive kod roditelja. Uživanje u alkoholnim pićima u većoj mjeri je kod studenata koji žive samostalno zbog smanjene kontrole i nadzora roditelja ili odgajatelja. U odnosu na spolnu strukturu (Rakić DB i sur.) dokazali su da u većini europskih zemalja muškarci češće piju alkoholna pića od žena, izuzev tri zemlje u Europi (Island, Latvija, Švedska) i Sjedinjenih Američkih Država (SAD) gdje žene češće piju alkoholna pića (21). Analizom rezultata pokazalo se da studenti koji žive kod roditelja tijekom studija imaju bolju kvalitetu života, fizičko funkcioniranje, percepciju općeg zdravlja i tjelesne boli (Tab. 2 prikazana u rezultatima). Rezultati nacionalne studije kvalitete života $\mathrm{u}$ Australiji govore o boljim vrijednostima kvalitete života studenata koji žive kod roditelja u odnosu na studente koji su podstanari u mjestu studiranja. U istraživanjima provedenim u zapadnim zemljama nije pronađena razlika u psihofizičkom funkcioniranju i subjektivnoj kvaliteti života među studentima koji žive kod roditelja i koji žive kao podstanari (22).

U ovom istraživanju kvaliteta života studenata također je bazirana na samoprocjeni zdravstvenog stanja mladih ljudi, dok drugi autori (npr. američki) svoje istraživanje usmjeravaju na mjerenje subjektivne kvalitete života, odnosno mjerenja zadovoljstva i sreće (4). 


\section{ZAKLJUČCI}

1. Studenti koji žive kod roditelja imaju bolju kvalitetu života u odnosu na studente koji žive kao podstanari.

2. Studenti koji žive kod roditelja žele nastaviti svoje obrazovanje, a studenti koji žive kao podstanari žele stupiti u radni odnos nakon završetka preddiplomskog studija.

3. Veći broj pušača je kod studenata koji žive kod roditelja, ali u manjim količinama puše cigarete, u odnosu na studente koji žive kao podstanari, gdje je manji broj pušača, a u većim količinama puše cigarete.

4. Studenti koji žive kao podstanari u većim količinama piju alkoholna pića jer su bez konstantnog nadzora roditelja ili odgajatelja u odnosu na studente koji žive kod roditelja u vrijeme studiranja.

5. Studenti koji žive kod roditelja smatraju da će postići bolje uspjehe i rezultate tijekom svoga obrazovanja u odnosu na studente koji žive kao podstanari.

\section{LITERATURA}

1. World Health Organization, Development of the World Health Organization WHOQOL-BREF quality of life assessment. The WHOQOL Group. Psychological Medicine, 1998; 28:551-8.

2. Varela-Mato V, Cancela JM, Ayan C, Martín V, Molina A. Lifestyle and Health among Spanish University Students: Differences by Gender and Academic Discipline. International Journal of Environmental Research and Public Health. 2012; 9(8):2728-41.

3. Gava-Protić B, Mikalački M, Šćepanović T. Bezbedan i zdrav život studenata bez duvanskog dima. Teme. 2013; 37(2):955-69.

4. Lučev, I. i Tadinac, M. Kvaliteta života u Hrvatskoj - povezanost subjektivnih i objektivnih indikatora te temperamenta i demografskih varijabli s osvrtom na manjinski status. Migracijske i etničke teme, 2008; 24(1-2).67-89.

5. Bowling, A. What things are important in people's lives? A survey of the public's judgements to inform scales of health related quality of life. Soc. Sci. and Medicine, 1995; 41(10):1447.
6. Bergner M, Bobbit R, Carter W. Gilson B. The Sickness Impact Profile: Development and final revision of a health status measure. Medical Care, 1981; 19:787-805.

7. Ware JE. SF-36 Health Survey: Manual \& interpretation guide. Boston, MA: The Health Institute, New England Medical Center; 1993.

8. The World Health Organization Quality of Life Group The World Health Organization Quality of Life Assessment (WHOQOL-BREF): Introduction, administration, scoring and generic version of the assessment. Field trial version. Geneva: Programme on mental health; 1996.

9. Meenan RF, Gertman PM, Mason JH. Measuring health status in arthritis: The Arthritis Impact Measurement Scales. Arthritis and Rheumatism, 1980; 23, 146-152.

10. Beck AT, Ward CH, Mendelson M, Mock J, Erbaugh J. An inventory for measuring depression. Archives of General Psychiatry. 1961; 4:561-571.

11. Hagerty MR, Cummins RA, Ferriss AL, i sur. Quality of life indexes for nationalpolicy: review and agenda for research. Social Indicators Research, 2001; 55:1-96.

12. Diener E, Suh EM, Lucas R, Smith HL. Subjective Well-Being: Three Decades of Progress, Psychological Bulletin, 1999.

13. Diener, E, Suh, E. Measuring quality of life: economic, social and subjective indicators, Social indicators research, 1997; 40:189-216.

14. Diener E, Suh EM. Lucas, R. i Smith, H. L. Subjective Well-Being: Three Decades of Progress, Psychological Bulletin, 1999; 125(2).

15. Oliver N, Holloway F, Carson J. Deconstructing quality of life, Journal of Mental Health. 1995; 4:1-4.

16. Cummins RA. R Eckersley J. Pallant J. van Vugt i Misajon, R. Developing a national index of subjective wellbeing: the Australian unity wellbeing index, Social Indicators Research, 2003; 64:159-190.

17.Cummins RA, Eckersley R, Pallant J, van Vugt J, Misajon R. „Developing a national index of subjective wellbeing: The Australian unity wellbeing index", Social Indicators Research 2003b; 64(2):159-190. 
18. Kuznar-Kaminska B, Brajer B, Batura-Gabryel H, Kaminski J. Tobacco smoking behavior among high school students in Poland. Physiol Pharmacol, 2008; 59:393-9

19. Steptoe A, Wardle J. Health behaviour, risk awareness and emotional wellbeing in students from Eastern Europe and Western Europe. Social Science \& Medicine, 2001; 53:1621-1630.
20.Rakić DB, Rakić B, Milošević Z, Nedeljković I. Rasprostranjenost upotrebe psihoaktivnih supstanci kod adolescenata i njena povezanost sa sociodemografskim faktorima. Vojnosanitetski pregled. 2014; 71(5):467-73.

21.Australian Unity Well-begin index. Dostupno: http://www.australianunity.com.au/about-us/ wellbeing/auwbi (Pristupljeno: 9. veljače 2017.). 


\title{
QUALITY OF ㄴIFE OF STUDENTS AT THE UNIVERSITY OF MOSTAR
}

\author{
Dajana Šimić ${ }^{1}$, Dragan Babić ${ }^{1,2}$ \\ ${ }^{1}$ Faculty of Health Studies, University of Mostar, Bosnia and Herzegovina \\ ${ }^{2}$ Clinic for Psychiatry, University Clinical Hospital Mostar, Bosnia and Herzegovina
}

\begin{abstract}
INTRODUCTION: Students are faced with many burdens and as a result they have no time for rest and sleep, physical and recreational activities, and also altered health habits which lead to improper diet, excessive use of alcohol, smoking and the use of psychoactive substances. All of the mentioned can affect their quality of life.

OBJECTIVE: Examine the quality of life of students at the University of Mostar.

SUBJECTS AND METHODS: the survey was conducted among students of both sexes, by random selection. The test group consisted of students who live as tenants $(\mathrm{N}=100)$, and the control group consisted of students who live with their parents $(\mathrm{N}=100)$. We used questionnaires: The socio-demographic questionnaire and standardized questionnaire for assessment of quality of life (short from health survey-36, SF-36).

RESULTS: Statistically a significantly lager number of students who live with their parents smoke, but fewer cigarettes, as opposed to students who live as tenants. Students who live as tenants drink more alcohol and drink more often than students who live with their parents. Students who live with their parents have a significantly better quality of life in the form of physical functioning, general health perception and physical pain.
\end{abstract}

CONCLUSION: Students who live their parents have a better quality of life when compared to students who live as tenants.

Key words: quality of life, students, University of Mostar

Correspondence:

Dajana Šimić

e-mail: simic.dajana@live.com 